$\left.\begin{array}{l}\text { Sournals } \\ \text { INTERNATIONAL JOURNAL OF } \\ \text { ORGANIZATIONAL LEADERSHIP }\end{array}\right) \begin{gathered}\text { INDUSTRIAL } \\ \text { MANAGEMENT } \\ \text { INSTITUTE }\end{gathered}$

\title{
The leadership styles dilemma in the business world
}

\author{
Mujahid Hussain $^{1 *}$, Hamid Hassan ${ }^{2}$ \\ ${ }^{1} \mathrm{PhD}$ Candidate, FAST School of Management, National University of Computer and Emerging Sciences \\ (FAST-NUCES), Lahore, Pakistan \\ ${ }^{2}$ Head, FAST School of Management, National University of Computer and Emerging Sciences (FAST- \\ NUCES), Lahore, Pakistan
}

\begin{abstract}
Keywords:

Leadership Styles, Factor Analysis, Leadership Styles Integration

Received

03 April 2016

Received in revised form 04 September 2016

Accepted

13 September 2016

Correspondence:

mujahid612@yahoo.com

The present study is an exploratory study that is conducted in 31 companies of automobile parts and accessories manufacturers located at Lahore, Pakistan to integrate dozens of leadership styles available in leadership literature. Factor analysis technique was used for dimensions reduction. SPSS and smartPLS3 software were used for data analysis. The study identified four basic leadership styles that could represent most of the leadership styles available in the literature. The results resemble leadership studies conducted at Ohio and Michigan State Universities with one basic difference of the dimensions suggested by the researchers to explain leadership styles, which are consultation and the relationship instead of task oriented and relationship oriented dimensions. The concept of representative leadership styles will make it simple to understand and handier to practice leadership styles' theories. The representative leadership styles will add a new perspective about the relationship and mutual exclusiveness of different leadership styles by looking at the bigger picture that was sketched through micro level studies. Research will help organizations in hiring of new leadership and in the setting priorities of leadership development. Though this study has been carried out in Pakistan but due to the size of the sample and extensiveness of the study its results can be considered generalizable.
\end{abstract}

Experts on the subject of leadership claim that leadership matters in success or failure of organizations (Bennis, 2007). Scholars and practitioners recognize leadership as a major element for affecting organizational performance (Bass, 1985; Cannella \& Rowe, 1995; Rowe, Cannella, Rankin, \& Gorman, 2005). The researchers positively concluded that effective leadership helps to enhance the performance of organizations and facilitates the attainment of desired goals (Bass, 1985; Gordon \& Yukl, 2004). The negative effects of ineffective 
leadership on performance of the organization and employees' attitudes also prove the importance and significance of effective leadership. A recent study conducted to examine the effects of ineffective leadership showed that there is a significant relationship between ineffective leadership and the negative aspects of employees' performance such as reduced output, bunking off, and negligence (Amabile, Schatzel, Moneta, \& Kramer, 2004). Hence, where the effective leadership helps in enhancing the performance of organizations leading to the attainment of desired goals, the ineffective leadership has negative impact on organizational performance and attitudes of employees.

The question now arises that what is the leadership? Gardner (1990) defined leadership as the process of persuasion by which an individual (or leadership team) induces a group to pursue objectives held by the leader or shared by the leader and his or her followers. Considering this definition to be effective in conveying the essence, it can be then said that leadership style is the way in which the followers are led. Therefore, the leadership style (if effective) may expand the performance of organizations and also help in the attainment of desired goals or (if ineffective) have negative impact on organizational performance and attitudes of employees. This strong relationship between leadership styles and organizational performance lured many scholars to study the phenomenon of leadership extensively that resulted into numerous leadership theories. Each theory suggests a different model and most often a different set of leadership styles for effectiveness of the leadership. The number of leadership styles in the leadership literature has been therefore, increasing as the study of leadership has evolved over the course of history.

Which one of the various leadership styles a leader should choose to follow to boost the performance of organization and which style one should avoid so that the negative effects on performance and attitudes of employees are effectively controlled? Making a choice between leadership styles is extremely difficult because dozens and dozens of overlapping leadership styles are found in the leadership literature. All the scholars of leadership have been zooming in and discovering newer and newer leadership styles and only a few of them who tried to zoom out and integrate or find out representative (few manageable) styles did so by ignoring some of the paradigms, thus resulting into waste of huge amount of leadership research.

In this study, we have made an attempt to suggest a new typology in order to merge all the leadership styles available in the literature into few manageable styles according to a generalized formula. This will make these styles easy to use for the busy leaders of today's business world. This sketching of the representative styles of leadership will be done on the basis of accumulations from large number of thinly focused modern studies defining several dozens of leadership styles without explaining their mutual exclusiveness. Several of the modern research endeavors on leadership are focused on distinct dimensions in close proximity that makes it difficult to define these dimensions in mutual exclusiveness. This study tooke into account the findings of these closes up attempts and zoom out to see the latest larger picture of leadership. This will help to compare the current sketch with the early studies that painted the broad outlines of leadership several decades back. This study makes a number of contributions to the literature on leadership. The concept of representative leadership styles will make it simple to understand and handier to practice leadership styles theories. The representative leadership styles will add a new perspective about the relationship and mutual exclusiveness of 
different leadership styles by looking at the bigger picture that is sketched through micro level studies. Research will help organizations in hiring of new leadership and in the setting priorities of leadership development. While study has been conducted within special context of Pakistan, it is expected that its findings are generalizable due to size of the sample and extensiveness of the study.

\section{The Research Problem}

With several dozens of leadership styles discussed in the literature, business leaders are confused as to what leadership style they need to follow. The dilemma extends into the domain of those who have to select leaders for various assignments in the organizations. The researchers posit that several dozens of leadership styles mentioned in the literature on leadership are in fact overlapping to a great extent, which can be represented by few basic styles. The research problem, therefore, is as follows:

- What are the basic leadership styles, which can represent most of the leadership styles identified in the leadership literature?

\section{Research Hypotheses}

Based on the research problem, the following hypotheses are provided and guided the study:

$\mathbf{H}_{\mathbf{0}}$ : The model described by 4 factors (integrated leadership styles) significantly ( $\mathrm{p}$-value $<.05$ ) represents all leadership styles commonly found in the literature.

$\mathbf{H}_{1}$ : The model described by 4 factors (integrated leadership styles) does not significantly (pvalue $<.05$ ) represent all leadership styles commonly found in the literature.

\section{The Literature Review}

A large number of theories of leadership developed during the later decades of the last century have resulted into balkanization in the leadership research. These studies have recommended a variety of leadership styles that could be practiced for enhancing organizational performance. These studies, however, did not attempt to describe mutual exclusiveness of the recommended leadership styles. Too many leadership styles complicate the situation for leaders to decide which style to follow and which one not to follow. Some leadership styles discussed in the leadership literature presented in Table 1 give a glimpse of the problem.

\section{Integration of Leadership Styles}

Some scholars have tried to coalesce the theories by developing and testing leadership philosophies from earlier balkanized perspectives. A few major efforts in this direction are mentioned here.

\section{Leadership Studies by University of Iowa}

Under the direction of Lewin, Lippitt, and White these studies were carried out in 1939. The studies proved to be very important and illustrated three leadership styles. They studied the performance of three groups of ten years old boys. The studies identified authoritarian, democratic, and Laissez-fair leadership styles. This was an effort to comprehend various leadership styles based on scientific grounds but being a study on ten years old boys, it cannot 
explain the qualities of adult leaders working in complex jobs. These studies limited leadership behavior to only one dimension, i.e. the control that in modern environments, where the work force is much educated, does not cover the whole spectrum of leadership effectiveness.

Table 1

Leadership Styles

\begin{tabular}{llll}
\hline Leadership Style & Latest Referred by & Leadership Style & Latest Referred by \\
\hline Autocratic & De Cremer, 2006 & Instrumental & Rees and Segal, 1984 \\
\hline Democratic & Woods, 2004 & Task Oriented & Yukl, 2012 \\
\hline Laissez-Faire & $\begin{array}{l}\text { Skogstad, Einarsen, Torsheim, } \\
\text { Aasland, and Hetland, 2007 }\end{array}$ & Delegative & Rees and Segal, 1984 \\
\hline Transformation-al & Bass and Stogdill, 1990 & Supportive & Pardey, 2008 \\
\hline Consultative & Hopkins and Putnam, 2013 & Relationship-Oriented & Bass and Stogdill, 1990 \\
\hline Malevolent & Woods, 2004 & Charismatic & Bass and Stogdill, 1990 \\
\hline Participative & Yukl, 2012 & Expressive & Groves, 2006 \\
\hline Transactional & Bass and Stogdill, 1990 & Visionary & Groves, 2006 \\
\hline Ethical & Toor and Ofori, 2009 & Pacesetting & Goleman, Boyatzis, and McKee, 2002 \\
\hline Authoritative & Bass and Stogdill, 1990 & Laissez-faire & De Cremer, 2006 \\
\hline Authoritarian & Bass and Stogdill, 1990 & E- leadership & Bennis, 2007 \\
\hline Servant & Yukl, 2012 & Authentic & Avolio and Bass, 1995 \\
\hline Advisory & Hopkins and Putnam, 2013 & Aversive & Stoller, Taylor, and Farver, 2013 \\
\hline Explosive & Motamedi, 1978 & Implosive & Motamedi, 1978 \\
\hline Abrasive & Motamedi, 1978 & Narcisstic & Motamedi, 1978 \\
\hline Impulsive & Motamedi, 1978 & Apprehensive & Motamedi, 1978 \\
\hline Primal & Goleman, Boyatzis, and McKee, 2002 & Tolerant & Goleman, Boyatzis, and McKee, 2002 \\
\hline Cultural & Cunningham and Gresso, 1993 & Conflict Inducer & Woods, 2004 \\
\hline Integrity & Craig and Gustafson, 1998 & Adaptive & Heifetz, Grashow, and Linsky, 2009 \\
\hline Shared & Ensley, Hmieleski, and Pearce, 2006 & Toxic & Kerr and Jermier, 1978 \\
\hline LMX & House, 1971 & Diplomatic & Woods, 2004 \\
\hline Situational & Fiedler and Garcia, 1987 & Consideration & Fiedler and Garcia, 1987 \\
\hline Directive & Kahai, Sosik, and Avolio, 2004 & & \\
\hline & & & \\
\hline
\end{tabular}

\section{Leadership Studies by Ohio State University}

Hemphill, Coons, Fleishman, Stogdill, Harris, and Burtt carried out these studies. These studies identified "Consideration" and "Initiating Structure" to be the underlying styles of leadership behavior. These styles were pinpointed as a result of a series of exploratory studies that explained through factor-analysis procedures the minimum number of aspects that best describe the leadership behavior.

\section{Leadership Studies by University of Michigan}

Likert, Katz, Maccoby, Kahn, and Morse were some of the original investigators. This group recognized two styles of leadership, namely production-centered and employee-centered. Initially, leaders of these two categories were thought to represent two opposite poles. However, later it was found out that these two categories were independent and can co-exist. Michigan State and Ohio State Universities studies are a great effort but the researchers opine that task orientation cannot be relegated to secondary position by any leader in any situation. How can a leader achieve his task without striving for it? 


\section{Studies of Tannenbaum and Schmidt (1958)}

Tannenbaum and Schmidt arranged six leadership styles (from authoritarian to delegating) according to the ratio of leader's scope for decision-making to the scope for decision-making of the group. The leadership can however not be limited to the decision making only, the successful implementation of the decision is more crucial to the success of the leaders.

\section{Global Leadership and Organizational Behavior Effectiveness (GLOBE) Research Program}

Van Wart (2003) declared that scholars should come up with and develop inclusive model of leadership, combine transformational and transactional elements, and also take into consideration public context and different situational variables inherent in that to advance understanding of public sector leadership. The "Global Leadership and Organizational Behavior Effectiveness" (GLOBE), Programme for Research was formulated by Wharton School of Business, University of Pennsylvania Professor Robert J. House in 1991. The responses of 17300 middle managers from 61 countries to 112 different qualities of leaders such as humility, decisiveness, trustworthiness, and dependence were studied by GLOBE. This assay resulted in formation of twenty-one leadership scales. Basing on a seven-point scale and world average of each (the mean of 61 countries), the twenty-one scales ranked from the "most universally desirable" to the "least universally desirable" which are shown in Table 2.

The 21 Leadership Scales Ranked From the "Most Universally Desirable" to the "Least Universally Desirable"

\begin{tabular}{ccc}
\hline Rank & Leadership Scales & Percentage \\
\hline 1 & Integrity & 6.07 \\
3 & Inspirational & 6.07 \\
4 & Visionary & 6.02 \\
5 & Performance-Oriented & 6.02 \\
6 & Team-Integrator & 5.88 \\
7 & Decisive & 5.80 \\
8 & Administratively Competent & 5.76 \\
9 & Diplomatic & 5.49 \\
10 & Collaborative Team Orientation & 5.46 \\
11 & Self-Sacrificial & 5.0 \\
12 & Modesty & 4.98 \\
13 & Humane & 4.78 \\
14 & Status Conscious & 4.34 \\
15 & Conflict Inducer & 3.97 \\
16 & Procedural & 3.87 \\
17 & Autonomous & 3.85 \\
18 & Face Saver & 2.92 \\
19 & Non-Participative & 2.66 \\
20 & Autocratic & 2.65 \\
21 & Self-Centered & 2.17
\end{tabular}

The six scales derived conceptually and statistically from these 21 scales were performance-oriented style, team-oriented style, participative style, humane style, autonomous style, and self-protective and group-protective style. These six styles, however, do not represent so many other leadership styles found in the literature including distributive, task 
oriented, and pacesetting. Moreover, some of the above mentioned 6 leadership styles have similar characteristics which could be clustered into one to two styles such as team-oriented style and participative style.

\section{ILM72-The Integrated Leadership Measure}

ILM72 provides that all leadership models emerge from six specific scales measuring different aspects of leadership style (Bass, 1985). ILM72 allows a person's leadership style to be measured against these six scales. The aspects which the six scales measure include task vs. person, flexible vs. dogmatic, de-centralized vs. centralized, reward vs. punishment, the means vs. the end, and structured vs. organic. There is duplication in ILM72 Model, e.g. task and the end.

\section{Important Leadership Styles and Questionnaires}

The leadership styles listed in Table 1 and others, found in the leadership literature may not all be important for a leader in most of the situations. Certain negative leadership styles such as narcissistic, abrasive and toxic styles also do not merit much of attention. This study is focused on leadership styles which are important and are often mentioned in the business world. These styles will then be integrated through factor analysis into integrated model of leadership styles. Twenty-eight such styles have been identified after a thorough review of leadership literature including the Bass and Avolio's handbook on leadership. These styles include authoritative style, laissez-faire style, democratic style, transactional style, transformational style, team oriented style, coercive style, visionary style, coaching style, affiliative style, pacesetting style, servant leadership style, shared leadership style, directive style, participative style, supportive style, achievement oriented style, tolerant style, consideration style, initiating structure style, task oriented style, relationship oriented style, telling style, selling style, consultative style, leaders-member exchange (LMX) style, authentic leadership style, and integrity leadership style. The questionnaires to measure these styles were also explored in the leadership literature. These questionnaires to measure 28 leadership styles were suitably modified as per the requirement of this study. These questionnaires were then combined into one tool to be filled by each leader. This combined questionnaire consisted of 264 questions which bring out score of each leader for above mentioned 28 leadership styles.

\section{Factor Analysis}

After a thorough review of statistical techniques like averaging, for dimensions reduction, factor analysis was found appropriate in the present study. Factor analysis shrinks and simplifies a large amount of data so that it has fewer dimensions and is more understandable. It uncovers hidden patterns, overlap of these patterns, and characteristics of varied patterns. It also creates variables (called dimensions) comprising of similar items in the set. There are two categories of factor analysis, namely exploratory and confirmatory. Exploratory factor analysis is used when the researchers are unaware about the structure or the dimensions of data. Being in line with the aim of this study, the researchers used this type of factor analysis for testing the framed hypotheses. Confirmatory factor analysis is used when one is completely aware of the structure and dimensions of variables of the data. In case of exploratory factor analysis, 
Jackson and Heuristic procedures to retain number of factors suggest that Eigenvalues larger than one should be retained (Guttman-Kaiser rule); the factors that account for almost $70-80 \%$ of variance should also be retained; and drawing a scree-plot should include all factors before the breaking point or elbow.

\section{Method}

The present study is basically a quantitative exploratory research using field survey design. A touch of qualitative research was given while naming the integrated leadership styles. The researchers selected automobile parts and accessories manufacturing industries for collecting data because of its large size. The instruments used were validated with positive results in terms of validity and reliability during the pilot study. The leadership styles of the sample leaders brought out through these tools were merged into limited number of representative leadership styles using factor analysis technique (as done in the Ohio State University Leadership Studies). The researchers used iterated principal axis factor as method of extraction with Eigen value $>1$ as the bottom line to limit the number of factors. Varimax Rotation was used to fit the factors better. The leadership styles merged were named using Delhie method. A demographic survey was conducted by the researchers to get the information regarding gender, highest level of education, age range, amount of time each participant worked for present employer and under present leader (in case of employees), and the participant's current position.

\section{Modification of Assessment Tools}

The current study involved filling up of a large questionnaire (resulting from a merger of 28 questionnaires) consisting of 264 questions. The scoring pattern of some questionnaires was modified to ensure uniformity and for better application of statistical tests. All items were positively phrased for easy handling of the data and to make calculations simple. The questionnaires were also modified to be acceptable to the subjects from their culture and faith point of view because asking certain question like those related to homosexuality could amount to annoying them and they would have refused to fill up even a single questionnaire. Some open-ended questions were converted into closed questions by identifying the possible range of answers.

\section{Sample and Sampling Method}

General guiding principles about size of sample for factor analysis include the Tabachnick's rule of thumb which proposes that for factor analysis at least 300 cases should be observed (Tabachnick, Barbara, \& Fidell, 2001). The sample size used in this study include 400 business leaders $(n=400)$. The list of companies which are members of Pakistan Association of Automotive parts and Accessories Manufacturers (PAAPAM) was taken as the research population for this study. There are total of 282 member industries of this association as per the PAAPAM Directory 2013-14. We tried to contact all the members industries of PAAPAM located at Lahore (116 in total) through the governing body of the association. However, only 31 companies agreed to participate in this study. Purposive sampling was used to select leaders with 15 to 25 subordinates because this is a reasonable number of employees whom the leaders 
can effectively influence and their effectiveness if assessed will be meaningful. Total of 400 leadership styles assessment questionnaires were distributed and out of those, 339 (84.7\%) questionnaires were returned. Out of 339 questionnaires received only 308 (77\% of the total distributed questionnaires) were found to be suitable for statistical analysis.

\section{Results}

An exploratory factor analysis was performed using all 28 leadership styles. Internal consistency was measured for all the 28 questionnaires using Cronbach's Alpha $>0.7$. Cronbach's Alpha was calculated to know and judge the internal consistency of all 28 questionnaires. The Cronbach's Alpha suggested that internal consistency of items (with Cronbach's Alpha $>0.7$ ) was high.

\section{Measures of Appropriateness of Factor Analysis (Reliability Statistics)}

Kaiser-Meyer-Olkin Test (KMO) measures the sampling adequacy which should be greater than 0.5 for a satisfactory factor analysis to proceed. According to Kaiser sampling, adequacy greater than 0.9 is superb. The KMO statistic of our sample is 0.952 which is superb. Bartlett's test indicates the strength of relationship among different variables. The test will suggest if the correlation matrix is an identity matrix or not. We can compare the observed correlation matrix to the identity matrix through Bartlett's test. In other words, it checks if there is a certain redundancy between the variables that the researchers can summarize with a few number of factors. The approximate of $\chi 2$ is 18061.99 with 378 degrees of freedom that confirms the model goodness of fit. The above findings indicated that all variables included in this study met the reliability and validity requirements of the standard survey. Study model and the data were appropriate for factor analysis.

\section{The Correlation Matrix}

The correlation matrix shows the correlations of every leadership style with every other leadership style included in the study. The correlation coefficients obtained present that quite a number of clusters have very high correlations and factor analysis will produce significant results.

\section{Total Variance}

Table 3 displays all the factors that can be extracted from the analysis along with their Eigenvalues, the cumulative variance of the factor and the prior factors, and the variance each factor can be attributed to.

Table 3

Total Variance

\begin{tabular}{ccccccc}
\hline & \multicolumn{3}{c}{ Initial Eigen Values } & \multicolumn{3}{c}{ Rotation Sums of Squared Loadings } \\
\cline { 2 - 7 } Component & Total & \% of Variance & Cumulative \% & Total & \% of Variance & Cumulative \% \\
\hline 1 & 16.51 & 58.96 & 58.96 & 8.25 & 29.48 & 29.48 \\
2 & 5.06 & 18.08 & 77.05 & 7.17 & 25.63 & 55.11 \\
3 & 1.77 & 6.35 & 83.40 & 6.57 & 23.47 & 78.58 \\
4 & 1.11 & 3.98 & 87.39 & 2.46 & 8.80 & $87.39 *$ \\
\hline
\end{tabular}


As per the Eigen values four factors can be extracted. The section related to the "Rotation Sums of Squared Loadings" displays the factors that met the decisive criterion (extraction method). In this analysis, a total of four factors with Eigen values greater than 1 existed there. The "\% of variance" column explains that each of these summary scales or factors can account for this much of the total variability in all of the variables together. The first factor produces $58.96 \%$ of total variance and the second, third, and the fourth factors produces $18.08 \%, 6.35 \%$, and $3.98 \%$ of total variance, respectively. Not all the factors left are significant because they explain the variance less than 1 only. Cumulatively, these four factors account for $* 87.39 \%$ of the variability in all 28 leadership styles which is quite satisfactory.

\section{Rotated Component (Factor) Matrix}

The researchers could extract four factors having significant loading of all 28 leadership styles. The contribution of the leadership style to the factor is directly proportional to the absolute value of loading. The rotation concluded in only 11 iterations. The rotated component matrix is shown in Table 4.

Table 4

Rotated Component (Factor) Matrix

\begin{tabular}{|c|c|c|c|c|}
\hline & \multicolumn{4}{|c|}{ Rotated Component Matrix (without suppression) } \\
\hline & \multicolumn{4}{|c|}{ Component } \\
\hline & 1 & 2 & 3 & 4 \\
\hline Auth & -.109 & .915 & -.199 & .061 \\
\hline Demo & .227 & -.297 & .731 & .181 \\
\hline Laissez & .258 & -.392 & .432 & .009 \\
\hline Transac & -.200 & .854 & -.375 & .151 \\
\hline Transf & .877 & -.183 & .314 & .093 \\
\hline Team & .557 & -.375 & .657 & -.175 \\
\hline Coers & -.212 & .853 & -.376 & .144 \\
\hline Vision & -.122 & .931 & -.201 & .080 \\
\hline Coaching & .761 & -.238 & .337 & -.303 \\
\hline Affiliative & .731 & -.149 & .471 & .260 \\
\hline Pacesetting & .234 & .204 & -.006 & .924 \\
\hline Serv & .794 & -.041 & .392 & .368 \\
\hline Shared & .734 & -.193 & .521 & .289 \\
\hline Directive & .297 & .253 & -.066 & .878 \\
\hline Supportive & .786 & .044 & .450 & .262 \\
\hline Participative & .600 & -.351 & .645 & -.077 \\
\hline Achievement & -.210 & .852 & -.376 & .151 \\
\hline Tolerant & .874 & -.184 & .319 & .084 \\
\hline Consider & .761 & -.108 & .538 & .297 \\
\hline Initiating & -.336 & .518 & -.719 & .183 \\
\hline Task & -.175 & .583 & -.533 & .173 \\
\hline Relation & .716 & -.196 & .601 & .126 \\
\hline Telling & -.105 & .932 & -.216 & .091 \\
\hline Selling & .407 & -.390 & .778 & -.125 \\
\hline Consult & .448 & -.370 & .784 & .004 \\
\hline LMX & .332 & -.302 & .775 & -.064 \\
\hline Authen & .747 & -.518 & -.017 & .126 \\
\hline Integrity & .673 & -.562 & -.118 & .144 \\
\hline
\end{tabular}
a. Extraction Method: Principal Component Analysis
b. Rotation Method: Varimax with Kaiser Normalization
c. Rotation Converged in 11 iterations
d. 4 Components Extracted 
Looking at Table 4, the researchers can observe that pacesetting and directing leadership styles significantly loaded on Factor 4; democratic, laissez-faire, team, participating, selling, consultative, and LMX leadership styles are substantially loaded on Factor 3 while authoritative, transactional, coercive, visionary, achievement oriented, initiating structure, task oriented, and telling leadership styles are significantly loaded on Factor 2. Following this, the remaining styles are considerably loaded on Factor 1. For more analysis, these factors can be used. The leadership styles, which have high factor loading on Factor 1 indicate that these styles can be described by hidden Factor 1. Other leadership styles cannot be described by hidden Factor 1 because their factor loadings on hidden Factor 1 are too small (less than or equal to .70). The sign on the loading $(-/+)$ refers to the way the item relates to the factor. For example, on the Factor 1 the authoritative leadership style has a negative loading such as 0.109 because this item is in opposition to the factor. It means that people who score high on leadership style will score low on the factor and vice versa. The leadership styles with high factor loading on one of the four factors were grouped together into a new integrated leadership style as follows:

\section{Integrated Style 1}

The leadership styles which loaded high on this factor include transformational, coaching, affiliative, servant, shared, supportive, tolerant, consideration, relationship oriented, and authentic and integrity leadership styles.

\section{Integrated Style 2}

The leadership styles which loaded high on this factor are authoritative, transactional, coercive, visionary, achievement oriented, initiating structure, task oriented, and telling leadership styles.

\section{Integrated Style 3}

The leadership styles which loaded high on this factor involve democratic, laissez-faire, team, participating, selling, LMX, and consultative leadership styles.

\section{Integrated Style 4}

The leadership styles which loaded high on this factor contain pacesetting and directing leadership styles.

The results are shown diagrammatically in Figure 1. 


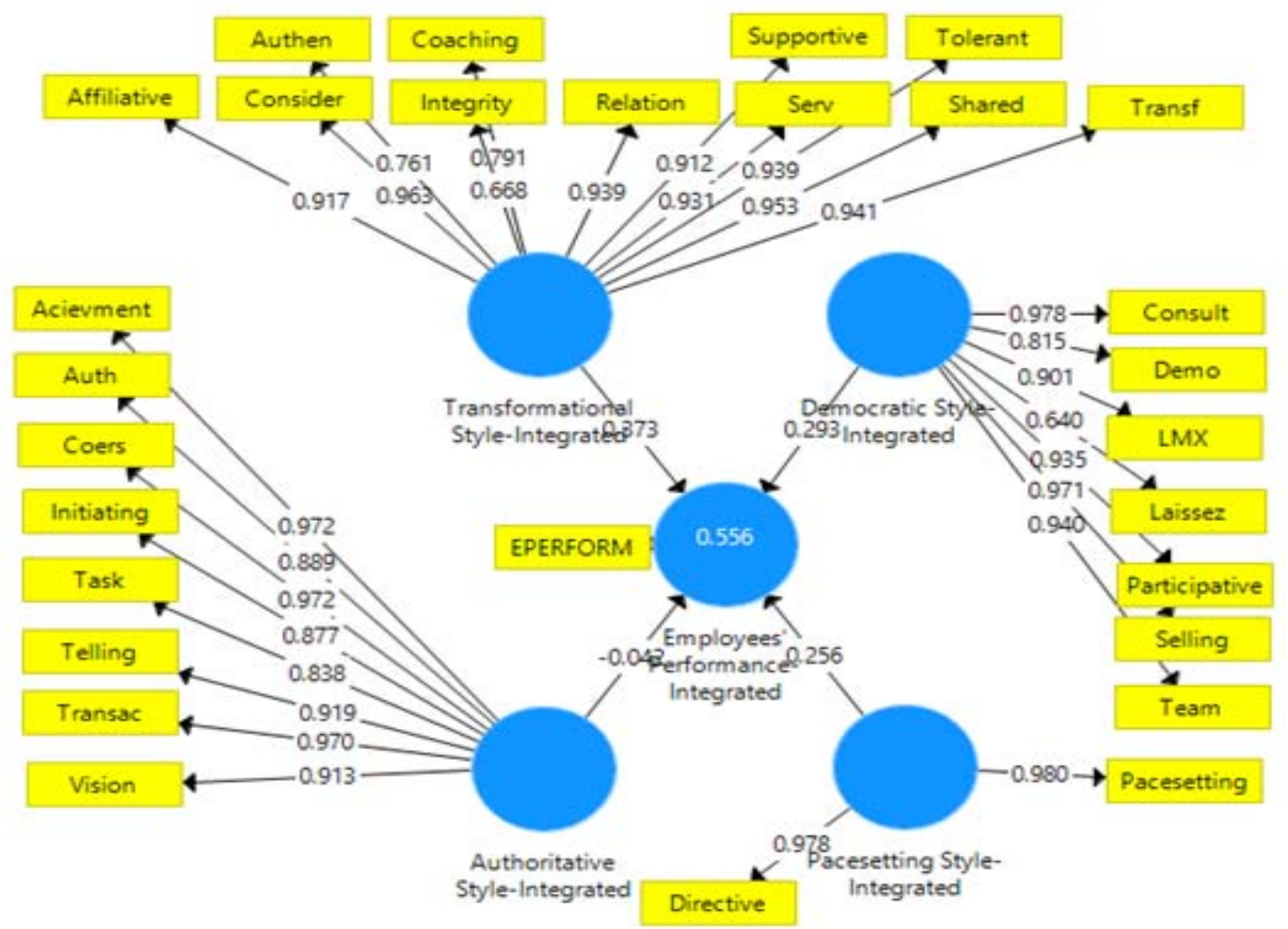

Figure 1. Factor analysis

\section{Naming the Newly Integrated Leadership Styles}

In order to name the new integrated leadership styles, the researchers used qualitative method of focus group research. The focus group consisted of $6 \mathrm{PhD}$ scholars of Management Sciences from University of Management and Technology of Lahore, Pakistan. These PhD scholars work their $\mathrm{PhD}$ thesis on leadership. They have carried out extensive literature review and have the experience of leading 20 to 25 followers. The focus group concluded that the new leadership styles should be named after the most familiar leadership style being merged in that new leadership style and recommended that in case of Factor 1, it should be transformational leadership style; in case of Factor 2, it should be authoritative leadership style; in case of Factor 3 , it should be democratic leadership style; and in case of Factor 4, it should be pacesetting leadership style after which the respective leadership styles may be named.

\section{Discussion}

Leadership studies by University of Iowa carried out in the 1939 by Lewin, Lippitt, and White, under the direction of Lewin identified authoritarian, democratic, and laissez-fair leadership styles. Leadership studies by Ohio State University identified "Consideration" and "Initiating Structure" to be the underlying styles of leadership behavior. Leadership studies by University of Michigan recognized two styles of leadership, namely production-centered and employeecentered. Six leadership styles (from authoritarian to delegating) were arranged by Tannenbaum and Schmidt (1958) according to the ratio of scope for decision-making of the leader to the scope of the group's decision-making. All early leadership theories suggest that leadership consists of influential as well as persuasive elements. The responses of 17300 middle managers from 61 countries to 112 different qualities of a leader such as humility, 
decisiveness, trustworthiness, and dependence were studied by Global Leadership and Organizational Behavior Effectiveness (GLOBE) (Van Wart, 2003). Within the variety of leadership styles the researchers found that quite a number of leadership styles are correlated explaining the same very dimension of leader's effectiveness. This study identified different threads to integrate the variety of leadership styles. As per the Rotated Component Matrix, the researchers could extract four factors.

The researchers proposed that the fundamental styles of leadership for a leader of any department, company, team, family, or even country could be explained by the four basic styles only. The understanding of these styles is therefore an essential knowledge for leadership gurus. The researchers did not suggest new styles for simplicity; giving new names may amount to adding new leadership style to already cluttered leadership literature. In case of exploratory factor analysis, when one is simply trying to understand the data, it is assumed that one variable can sufficiently explain a factor. In these cases, one variable must have a very high factor loading (+/- 0.7 or greater) on the factor that it is explaining. However, when factor analysis is carried out as a precursor to further analyses, four different variables, or minimum of two variables should load moderately high (+/- 0.5 or greater) on the factor. In this study, we retained every factor that loaded highly on one factor. Also of note is that all four factors have variable loadings of at least 0.5 .

Laissez Faire leadership style does not show any pattern and according to researchers' opinion, it may not be considered as leadership style. It did not load high on any of the four factors. Its highest loading was on democratic-integrated style that does not seem to be very convincing. This is because most of the leaders did not consider it a leadership style at all. This style may be eliminated from the list of leadership styles based on some more studies aimed specifically to study this particular leadership style. For understanding of newly integrated styles, the interested leaders can refer to the relevant literature on leadership styles. To understand transformational-integrated, authoritative-integrated, democratic-integrated, and pacesetting-integrated the leaders can study transformational, telling, consultative, and pacesetting styles, respectively because these styles have highest loadings on the respective factors. After having grouped the leadership styles, the next task was to name these newly integrated leadership styles, which was done using focus group research method. The focus group in line with the basic philosophy of this study which is to simplify the whole scenario suggested to use existing names instead of adding more styles (names) to already saturated leadership literature. The leadership styles loading high on a factor are like the parent of a newborn, whose face one wants to see before giving it a name. The newly integrated leadership styles were named as per the focus group's best judgment. The number of components extracted through factor analysis was four. The focus group concluded that the new leadership styles should be named after the most familiar leadership style being merged in that new leadership style and recommended that in case of Factor 1, it is transformational leadership style; in case of Factor 2, it is authoritative leadership style; in case of Factor 3, it is democratic leadership style; and in case of Factor 4, it is pacesetting leadership style after which the respective leadership styles may be named.

The reduction of leadership styles into fewer number of leadership styles may not be surprising because many other studies have also been pointing to somewhat similar findings; 
the significance of this study is due to the fact that it has identified different dimensions which explain the leadership styles more effectively. A critical look at the leadership styles grouped together reveals that two threads, which run through the four factors, are consultation and consideration. Ohio State University and Michigan University leadership studies identified two dimensions of leadership styles, namely task orientation (initiating structure scale) and relationship oriented (consideration scale). The researchers opine that task orientation is a universal requirement for any leader. If a leader is not task oriented, then what is he being paid for? Every leader has to be task oriented to produce desired results. Out of the other two terms, relation oriented and consideration scale used by Ohio State University and Michigan State University, respectively, to convey the same meaning; consideration scale is considered to be more appropriate because as far as relationship is concerned, every leader will develop understanding over a period of time. Considering individual needs of employees may be a concern of a leader or otherwise. This model tried to define leadership styles using the consultation and consideration dimensions. The two dimensions are not mutually exclusive. A leader can be high or low on both dimensions at the same time or low on one and high on the other one. Using these two dimensions, a leader can have one of the following four leadership styles including high consideration-high consultation (transformational-integrated); low consideration-low consultation (pacesetting-integrated); low consideration-high consultation (democratic-integrated); and high consideration-low consultation (authoritative-integrated).

\section{TAPD (Transformational, Authoritative, Pacesetting and Democratic) Model of Leadership Styles}

Based on the findings of this study, the researchers propose an integrated leadership styles model which can be used to explain most of the leadership styles found in the leadership literature. Consultation and relationship are the two threads running through these leadership styles. The suggested leadership styles model (TAPD model of leadership styles) emerged is presented in Figure 2.

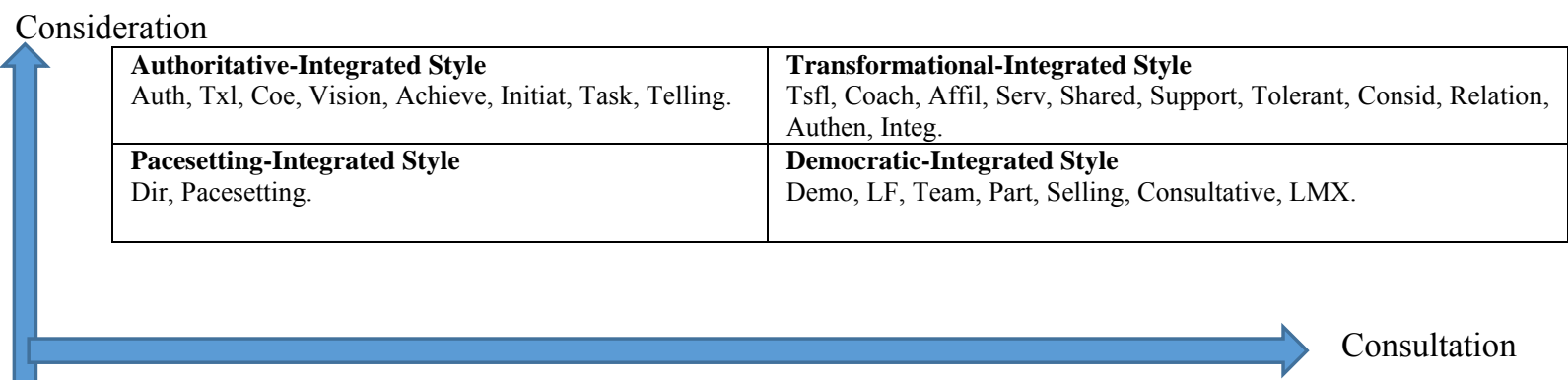

Figure 2. TAPD model of leadership styles

\section{Conclusion}

Extensive research is being carried out on leadership because it plays crucial role in success of organizations. The way leaders lead their organizations is not similar; this unique way of leading is called leadership style. The effectiveness of an organization highly depends on the leadership styles. Some of the leadership styles such as ethical style and authentic style are 
compulsion of a leader without which there cannot be any meaningful discourse between the leader and the employees. Enormousness of the leadership styles defeats the end and makes it unmanageable for the busy leaders to benefit from all this research. This study integrated popular leadership styles. The researchers hope that the future studies on leadership will try to reverse the process of proliferation of leadership literature with leadership styles and help in making the leadership studies easy for the leaders to practice. The researchers would urge other leadership scholars to carry out more research aimed at integrating number of thinly focused theories and perspectives on leadership leading to the larger picture of leadership.

This study approached the topic of leadership as a generalized process, whereas the latest trend studies the subject with more narrow focus on the effect of the leadership styles and behaviors which differ across employees, jobs, and organizations (Aime, Johnson, Ridge, \& Hill, 2010). The researchers cannot deny the logic of such research but where such research may be useful for deeper understanding of the leadership process, the researchers think that there is a requirement to compare and contrast these newer perspectives of leadership with the older hierarchical approach of leadership; so that the process of integrative understanding of leadership processes in organizations keeps pace with the thinly focused differentiated studies of leadership processes. The researchers suggest that this research may also be replicated in different environments. There is a need to develop a questionnaire to assess the newly identified integrated leadership styles. For effective use of these styles by those who have to select leaders for different assignments, there is a need to find relationship of these styles with organizational performance and the impact of various moderating factors like the stages of organizational life cycle and the leader's self-efficacy.

\section{References}

Aime, F., Johnson, S., Ridge, J. W., \& Hill, A. D. (2010). The routine may be stable but the advantage is not: competitive implications of key employee mobility. Strategic Management Journal, 31(1), 75-87.

Amabile, T., Schatzel, E., Moneta, G., \& Kramer, S. (2004). Leader behaviors and the work environment for creativity: Perceived leader support. The Leadership Quarterly, 15(1), 5-32.

Avolio, B., \& Bass, B. (1995). Individual consideration viewed at multiple levels of analysis: A multi-level framework for examining the diffusion of transformational leadership. The Leadership Quarterly, 6(2), 199-218.

Bass, B. M. (1985). Leadership and performance beyond expectations. New York: Free Press.

Bass, B., \& Stogdill, R. (1990). Bass \& Stogdill's handbook of leadership. New York: Free Press.

Bennis, W. (2007). The challenges of leadership in the modern world: Introduction to the special issue. American Psychologist, 62(1), 2-5.

Cannella, A. A., \& Rowe, W. G. (1995). Leader capabilities, succession, and competitive context: A study of professional baseball teams. The Leadership Quarterly, 6(1), 69-88.

Craig, S., \& Gustafson, S. (1998). Perceived leader integrity scale: An instrument for assessing employee perceptions of leader integrity. The Leadership Quarterly, 9(2), 127-145.

Cunningham, W., \& Gresso, D. (1993). Cultural leadership: The culture of excellence in education. Boston: Allyn \& Bacon.

De Cremer, D. (2006). Affective and motivational consequences of leader self-sacrifice: The moderating effect of autocratic leadership. The Leadership Quarterly, 17(1), 79-93.

Ensley, M., Hmieleski, K., \& Pearce, C. (2006). The importance of vertical and shared leadership within new venture top management teams: Implications for the performance of startups. The Leadership Quarterly, 17(3), 217-231.

Fiedler, F., \& Garcia, J. (1987). New approaches to effective leadership: Cognitive resources and organizational performance. New York: Wiley.

Gardner, J. (1990). On leadership. New York, NY: The Free Press. 
Goleman, D., Boyatzis, R. E., \& McKee, A. (2002). Primal leadership: Realizing the power of emotional intelligence. Boston, Mass.: Harvard Business School Press.

Gordon, A. \& Yukl, G. (2004). The future of leadership research: Challenges and opportunities. German Journal of Human Resource Management, 18(3), 359-365.

Groves, R. (2006). Nonresponse rates and nonresponse bias in household surveys. Public Opinion Quarterly, 70(5), 646-675.

Heifetz, R., Grashow, A., \& Linsky, M. (2009). The practice of adaptive leadership. Boston, MA: Harvard Business Press.

Hopkins, D., \& Putnam, R. (2013). Personal growth thru adventure. Hoboken: Taylor \& Francis.

House, R. (1971). A path goal theory of leader effectiveness. Administrative Science Quarterly, 16(3), 321-321.

Kahai, S., Sosik, J., \& Avolio, B. (2004). Effects of participative and directive leadership in electronic groups. Group \& Organization Management, 29(1), 67-105.

Kerr, S., \& Jermier, J. M. (1978). Substitutes for leadership: Their meaning and measurement. Organizational Behavior \& Human Performance, 22(3), 375-403.

Lewin, K., Lippitt, R., \& White, R. (1939). Patterns of aggressive behavior in experimentally created social climates. Journal of Social Psychology, 10, 271-99.

Motamedi, K. K. (1978). Toward explicating philosophical orientations in organizational behavior (OB). The Academy of Management Review, 3(2), 354-360.

Pardey, D. (2008). Next generation leaders. Strategic HR Review, 7(3), 32-36.

Rees, C. R., \& Segal, M. W. (1984). Role differentiation in groups: The relationship between instrumental and expressive leadership. Small Group Behavior, 15(1), 109-123.

Rowe, W. G., Cannella, A., Rankin, D., \& Gorman, D. (2005). Leader succession and organizational performance: Integrating the common-sense, ritual scapegoating, and vicious-circle succession theories. The Leadership Quarterly, 16(2), 197-219.

Skogstad, A., Einarsen, S., Torsheim, T., Aasland, M., \& Hetland, H. (2007). The destructiveness of laissez-faire leadership behavior. Journal of Occupational Health Psychology, 12(1), 80-92.

Stoller, J. K., Taylor, C. A., \& Farver, C. F. (2013). Emotional intelligence competencies provide a developmental curriculum for medical training. Medical Teacher, 35(3), 243-247.

Tabachnick, B., Barbara, G., \& Fidell, L. (2001). SAS for windows workbook for Tabachnick and Fidell using multivariate statistics ( $4^{\text {th }}$ ed.). Boston, Mass: Allyn \& Bacon.

Tannenbaum, R., \& Schmidt, W. (1958). How to choose leadership Pattern. Harvard Business Review, 36(2), 95-100.

Toor, S., \& Ofori, G. (2009). Authenticity and its influence on psychological well-being and contingent self-esteem of leaders in Singapore construction sector. Construction Management \& Economics, 27(3), 299-313.

Van Wart, M. (2003). Public-sector leadership theory: An assessment. Public Administration Review, 63(2), 214-228.

Woods, P. (2004). Democratic leadership: Drawing distinctions with distributed leadership. International Journal of Leadership in Education, 7(1), 3-26.

Yukl, G. (2012). Effective leadership behavior: What we know and what questions need more attention. Academy of Management Perspectives, 26(4), 66-85. 